\title{
NECESSIDADES DE TREINAMENTO ORGANIZACIONAL E MOTIVAÇÃO PARA
} TRABALHAR

\author{
Gisela Gomes da Silva \\ gomes.gisela@gmail.com \\ Universidade de Brasília - Brasília, DF / Brasil \\ Pedro Paulo Murce Meneses \\ pemeneses@yahoo.com.br \\ Universidade de Brasília - Brasília, DF / Brasil
}

\begin{abstract}
Recebido em 27/05/2010
Aprovado em 29/09/2011

Disponibilizado em 01/04/2012

Avaliado pelo sistema double blind review

Revista Eletrônica de Administração

Editor: Luís Felipe Nascimento

ISSN 1413-2311 (versão on-line)

Editada pela Escola de Administração da Universidade Federal do Rio Grande do Sul.

Periodicidade: Quadrimestral
\end{abstract}

Sistema requerido: Adobe Acrobat Read

\section{RESUMO}

Apesar de contribuir com a programação, a execução e a avaliação de resultados, a etapa de análise de necessidades tem sido constantemente negligenciada pela literatura científica e pela prática profissional de treinamento, cujos volumosos investimentos, portanto, tendem a ser desperdiçados. Os modelos que orientam este importante campo foram propostos há aproximadamente 50 anos, de forma que não são capazes, atualmente, de orientar teórica e metodologicamente estudiosos e praticantes da área. Nesse sentido, esta pesquisa objetivou, mediante execução de análise de covariância em amostra de 213 participantes, investigar a relação entre motivação para o trabalho e complexidade de necessidades de treinamento, com vistas a permitir a composição futura de modelos teóricos de análise de necessidades integrados, não apenas por componentes relacionados às tarefas, como prescrito na literatura, mas, também, por variáveis relativas aos níveis individual, grupal e organizacional de análise. Especificamente, quatro objetivos específicos, cada qual associado a procedimentos e técnicas de pesquisa particulares, foram determinados: (1) elaborar, por meio de pesquisa documental e grupo de foco, e validar, teórica e empiricamente, a partir de entrevista individual e realização de análises fatoriais exploratórias, instrumento para aferição das necessidades de treinamento; (2) adaptar e validar estatisticamente o instrumento de medida de motivação para trabalhar, também em função de análises fatoriais exploratórias; (3) com teste de diferença de médias entre amostras independentes, formar grupos de comparação em função do no nível de motivação para trabalhar dos respondentes; e (4) identificar variáveis de controle estatístico para composição do modelo final de investigação a partir de correlações bivariadas. Os resultados obtidos satisfizeram todos esses quatro objetivos intermediários de pesquisa: bons índices psicométricos de validação e confiabilidade dos instrumentos de necessidades e de motivação foram obtidos; dois grupos de comparação puderam ser estatisticamente formados em função dos níveis de motivação de seus integrantes; e o tempo de serviço pôde ser

REAd I Porto Alegre - Edição 71 - N 1 - janeiro/abril 2012 - p. 27-62 
Necessidades de treinamento organizacional e motivação para trabalhar

selecionado como variável de controle estatístico para a composição do modelo final de investigação. Apesar desses resultados positivos, a análise de covariância efetuada não evidenciou relação alguma entre motivação e necessidades de treinamento, contrariando parte da literatura, não diretamente relacionada à área de treinamento, que atesta esta relação direta. Este resultado torna necessária a ampliação e o aprofundamento de pesquisas nesse sentido, principalmente pelo fato de a motivação ser uma das principais variáveis individuais responsáveis pela explicação de medidas de desempenho pós-treinamento.

Palavras-chave: análise de necessidades de treinamento; motivação para o trabalho; treinamento e desenvolvimento de pessoas.

\title{
TRAINING NEEDS AND WORK MOTIVATION: ANALYSIS OF THE RELATIONSHIP
}

\begin{abstract}
Although contributing to the planning, execution and results evaluation, the needs analysis subsystem has been consistently neglected by the training scientific literature and professional practice, whose bulky investments, therefore, tend to be wasted. The models that guide this important field have been proposed about 50 years ago, so they are not capable, today, of theoretical and methodological guide scholars and practitioners in the area. Thus, this study aimed, through implementation of analysis of covariance in a sample of 213 participants, to investigate the relationship between motivation to work and complexity of training needs, in order to allow the composition of future needs analysis theoretical models integrated not only for components related to the tasks, as prescribed in the literature, but also by variables related to the individual, group and organizational level of analysis. Specifically, four specific objectives, each one associated with particular procedures and research techniques were determined: (1) developing, through documental research and focus group, and validate, theoretically and empirically, from individual interviews and exploratory factor analysis, instrument for measuring training needs; (2) adapt and statistically validate the instrument to measure motivation to work, also through of exploratory factor analysis; (3) to test for mean differences between independent samples produce comparison groups depending on the level of respondents' motivation to work; and (4) identifying control variables for statistical composition of the final research, from bivariate correlations. The results satisfied all of these four intermediate goals: good psychometric indices of reliability and validity of the instruments of needs and motivation were obtained; two groups could be statistically formed according to level of motivation of its members; and the time service might be selected as a control variable for the statistical composition of the final investigation model. Despite these positive results, the covariance analysis performed did not show any relation between motivation and training needs, contrary to conventional wisdom, not directly related to the training area, which certifies this direct relationship. This result makes it necessary to expand and deepen research in this direction, mainly because the motivation is one of the main individual variables responsible for the explanation of post-performance training measures.
\end{abstract}

Keywords: training needs analysis; work motivation; personnel training and development. 
Gisela Gomes da Silva \& Pedro Paulo Murce Meneses

\section{INTRODUÇÃO}

As rápidas mudanças tecnológicas, sociais, políticas e econômicas têm afetado incisivamente as dinâmicas das organizações contemporâneas. A instabilidade gerada repercute diretamente na busca por modelos eficientes de desenvolvimento de novas competências profissionais, de forma a garantir continuamente recursos e clientes para organizações inseridas em um cenário altamente competitivo. Nesse contexto, a área de treinamento, desenvolvimento e educação de pessoas (TD\&E) cada vez mais assume relevância nas organizações, pois, conforme destacam Loiola, Néris e Bastos (2006), a capacidade de aprender gera impactos positivos na sustentabilidade das condições de competitividade e de sobrevivência das organizações.

Mas para que tais impactos possam ser constatados e mesmo creditados à área, é preciso que necessidades de treinamento sejam devidamente identificadas nos diversos níveis de análise - organizacional, grupal e individual - geralmente focalizados em estudos organizacionais. É justamente na mensuração de lacunas de desempenho nesses níveis que a avaliação de necessidades de treinamento, objeto de estudo desta pesquisa, exerce seu papel. Entendida como subcampo de TD\&E, esta avaliação visa prescrever sobre o alinhamento entre ações de treinamento e objetivos organizacionais, as competências que devem ser desenvolvidas e as pessoas que demandam capacitação. Além disso, pretende agir sobre fatores do ambiente organizacional que têm relação com as variáveis que os sistemas de capacitação modificam, visando tornar mais efetiva a ação (PILATI, 2006) e, anteriormente, o cumprimento das etapas de planejamento e execução dos eventos de treinamento.

Pesquisadores e profissionais desta área afirmam que a avaliação de necessidades é uma das fases mais importantes de um sistema instrucional, porque eventuais falhas nessa fase repercutem negativamente nos demais subsistemas de TD\&E de planejamento, execução e avaliação de efeitos (ABBAD; FREITAS; PILATI, 2006). Apesar da relevância da avaliação de necessidades de treinamento para o sucesso das políticas e práticas de TD\&E, tanto a produção científica quanto a prática nas organizações revelam poucos avanços na área (AGUINIS; KRAIGER, 2009). Para Salas e Cannon-Bowers (2001), este subsistema continua caracterizado mais como uma arte do que uma ciência devido à pequena quantidade de trabalhos empíricos até então desenvolvidos.

Tannenbaum e Yulk (1992) revelaram, por exemplo, que apenas 27\% das empresas pesquisadas reportaram ter procedimentos para determinar as necessidades de treinamento e educacionais de seus gerentes. Conforme explica Borges-Andrade (2006), devido às 
Necessidades de treinamento organizacional e motivação para trabalhar

inúmeras, contínuas e velozes demandas por ações de treinamento, não é prática organizacional realizar um levantamento sistemático, com base em uma visão estratégica que leve em conta as mudanças que podem ocorrer nos postos de trabalho, as expectativas dos indivíduos e os objetivos organizacionais no presente e no futuro, para verificar o que o indivíduo faz e o que deveria fazer. Com isso, o problema (discrepância de desempenho) nunca é diagnosticado e logo se faz a prescrição da solução: alguma atividade de TD\&E.

É neste este amplo e pouco pesquisado tema, portanto, que se insere o presente estudo, cujo relato se origina de uma pesquisa, realizada em uma autarquia federal, concentrada no objetivo geral de analisar a relação entre motivação para o trabalho e autopercepção de necessidades de treinamento organizadas conforme nível de complexidade dos conteúdos das descrições comportamentais de conhecimentos, habilidades e atitudes. Para o teste desta relação, objeto central de atenção do presente relato teórico-empírico, fez-se necessário cumprir uma série de objetivos específicos, de modo a compor um desenho de pesquisa correlacional: (i) elaborar e validar, semântica e estatisticamente, instrumento para aferição das necessidades de TD\&E relacionadas à visão sistêmica de funcionários de determinada instituição pública; (ii) adaptar e validar estatisticamente instrumento de medida de motivação para trabalhar; (iii) constituir grupos de comparação em função do nível de motivação para trabalhar dos respondentes; e (iv) identificar variáveis de controle estatístico para composição do modelo final de investigação por meio de correlações bivariadas. Cumpridas tais etapas, a meta final do estudo pôde então ser satisfeita.

\section{REFERENCIAL TEÓRICO}

Necessidades de treinamento podem ser entendidas como lacunas nos repertórios de conhecimentos, habilidades e atitudes (CHAs) disponíveis para o trabalho individual ou de determinados grupos e equipes profissionais (ABBAD; FREITAS; PILATI, 2006). Gilbert (1978) e Mager e Pipe (1984) relacionam este hiato de competência a um problema de desempenho que pode ser causado por inúmeros fatores individuais ou contextuais. Conforme Abbad, Freitas e Pilati (2006), trata-se de um tipo especial de avaliação de desempenho para identificação de desvios ou discrepâncias entre os desempenhos observados e os esperados pela organização. Sem um entendimento claro dessas necessidades, os esforços de treinamento de uma organização podem perder completamente o rumo, resultando no desperdício total de recursos valiosos, na inadequação do desenho do programa de treinamento e dos outros estágios do processo de treinamento e na ausência de respostas 
organizacionais antecipadas que, não percebidas a tempo, tendem a influenciar negativamente as taxas de sobrevivência e competitividade das empresas (TAO; YEH; SUN, 2006).

Entre as abordagens mais bem difundidas nos círculos científicos e profissionais da área, tem-se o modelo proposto por McGehee e Thayer (1961), que organiza a avaliação de necessidades de treinamento (ANT) em três níveis de análise: organizacional (organization), de tarefas (task) e individual (person). Segundo este modelo, denominado de O-T-P, no nível organizacional deve ser especificado onde, na estrutura organizacional, o treinamento se faz necessário. $\mathrm{Na}$ análise de tarefas, determinam-se quais CHAs devem ser desenvolvidos para que se cumpram os padrões de desempenho determinados pelas organizações e respectivas unidades de trabalho. Na análise individual, por fim, identifica-se quem na organização precisa receber treinamento (TAYLOR; O’DRISCOLL; BINNING, 1998).

Apesar das ricas proposições, o modelo O-T-P ainda é caracterizado como parte de um enfoque que provê poucas informações sobre como escolher o melhor método e fonte de coleta de dados para a avaliação de necessidades em cada nível (MOORE; DUTTON, 1978). Além disso, Abbad, Freitas e Pilati (2006) salientam que ainda não houve pesquisas suficientes para criação de metodologias sistemáticas de avaliação integrada de necessidades nos diversos níveis de análise (indivíduo, tarefas, grupos ou equipes e organização), fato que explica, pelo menos em parte, os motivos de as organizações não contarem com práticas mais sistematizadas nesse sentido.

De fato, a baixa produção temática, como apontada pelos autores supracitados, constitui tendência na área desde sua consolidação, em meados da década de 1950, como campo científico de estudos. Nesse sentido, com vistas à identificação de padrões, tendências e desafios produtivos, foi revisada a literatura estrangeira e nacional que trata da ANT. No cenário estrangeiro, foram consultadas as revisões sobre TD\&E disponibilizadas no Annual Review of Psychology, jornal renomado que, periodicamente, sintetiza a produção mundial sobre o assunto (CAMPBELL, 1971; GOLDSTEIN, 1980; WEXLEY, 1984; LATHAM, 1988; TANNENBAUM; YUKL, 1992; SALLAS; CANNON-BOWERS, 2001; AGUINIS; KRAIGER, 2009). Em âmbito nacional, foram consultados artigos empíricos disponibilizados pela Internet em periódicos nacionais, classificados pelo sistema WebQualis entre os níveis A e C, nas áreas de Administração e Psicologia, de 1994 a 2010; e em dissertações e teses acadêmicas.

De maneira geral, a literatura internacional expõe poucos avanços desde a publicação do Modelo O-T-P. A publicação pioneira de Campbell (1971) apontou que pouco se fez sobre 
Necessidades de treinamento organizacional e motivação para trabalhar

o tema de ANT, uma vez que a reduzida quantidade de pesquisa científica localizada à época preocupou-se apenas com o desenvolvimento de métodos, especialmente aquele atualmente denominado de incidentes críticos, e de modelos de avaliação de necessidades, neste caso, com base em propostas de decomposição do desempenho humano em elementos passíveis de treinamento. Todas essas propostas enquadram-se no nível de tarefas, de forma que não se constatou produção sistemática nos demais níveis.

Já Goldstein (1980) apresentou alguns avanços nas pesquisas de ANT, ainda que concentradas nas análises de tarefas e de pessoas. Merece destaque metodologia específica para a descrição de tarefas e para o desenho de uma variedade de sistemas de escala para medir dimensões dessas tarefas, tais como: frequência, importância, periodicidade de realização e identificação do local onde a tarefa deve ser aprendida. Além disso, foi nessa época que se iniciou a utilização das taxonomias de aprendizagem na descrição e classificação de necessidades de treinamento. Nada de destaque sobre análises organizacionais foi observado.

Apesar desses avanços, a abordagem de McGehee e Thayer continuou sendo o modelo mais compreensível e sofisticado para considerar as necessidades de treinamento durante o intervalo de tempo analisado na revisão capitaneada por Wexley (1984). Este autor sugeriu que a clientela de TD\&E deveria ser consultada em relação à importância do conteúdo dos treinamentos e, assim, autoavaliações começaram a ser utilizadas, em vez de apenas consultas aos chefes imediatos e demais superiores. Outra sugestão abarcou o cômputo da discrepância entre comportamento real e comportamento ideal, ideia, inclusive, aproveitada na concepção mais difundida nacionalmente de ANT proposta por Borges-Andrade e Lima (1983), intitulada Metodologia da Análise do Papel Ocupacional. Mais uma vez, não foram notados avanços em relação à análise organizacional.

Na revisão realizada por Latham (1988), emerge a sugestão de que a ANT fosse feita com base em objetivos estratégicos futuros. Outra importante recomendação foi a inclusão de um quarto nível de análise (demográfico) para identificar as necessidades de diferentes grupos. Apesar de importante, essa sugestão ainda não foi ampla e definitivamente acatada pela ciência do treinamento.

Na revisão de Tannenbaum e Yukl (1992), foi apresentada uma expansão do modelo O-T-P: um modelo multinível de análises de necessidades de treinamento que abrangia a conceituação e a mensuração de variáveis relativas aos indivíduos, unidades e organização na operacionalização da análise organizacional, de tarefas e individual. Além disso, em 1998, 
Taylor, O`Driscoll e Binnig propuseram um modelo de ANT que integrava as abordagens de McGehee e Thayer (1961) e de Mager e Pipe (1984). Embora os avanços, o modelo tradicional baseado somente nos três níveis de análise (organizacional, de tarefas e individual) continuou sendo o mais utilizado.

Quase uma década depois, Salas e Cannon-Bowers (2001) reforçaram a necessidade de se incorporar variáveis referentes ao clima de trabalho na análise organizacional. No nível de tarefas, surge outra vertente de análise não direcionada para a determinação dos desempenhos a serem treinados, mas, sim, à forma como os indivíduos cognitivamente processam dados e informações. Trata-se da análise cognitiva de tarefas, cuja pretensão era permitir que a aprendizagem de tarefas, atividades, desempenhos etc., em situações de TD\&E, pudesse ser facilitada.

Por fim, na mais recente revisão no Annual Review of Psychology, Aguinis e Kraiger (2009) sugeriram a inclusão de especialistas em conteúdo (juízes) no processo de análise de tarefas e ressaltaram a importância de se certificar, antes do início do treinamento, do preparo e da motivação dos treinandos em relação ao treinamento. Mas diferentemente das revisões anteriores, esta última apenas tratou de alguns poucos avanços na área, a ponto de mencionar que a ANT ainda carece de produção teórica e empírica capaz de garantir os benefícios, em termos socioambientais, organizacionais, de grupos e equipes e individuais, retoricamente associados a programas de treinamento organizacional.

No Brasil, em função dos critérios de busca bibliográfica informados, uma quantidade ínfima de quatro artigos em 57 periódicos foi localizada, além de uma dissertação. Pesquisas como a de Magalhães e Borges-Andrade (2001) e Castro e Borges-Andrade (2004), por exemplo, trataram da aplicação do método da análise do papel ocupacional de BorgesAndrade e Lima (1983) e da manipulação de fontes de avaliação no processo de ANT para ocupantes de cargos específicos. Enquanto essas pesquisas concentraram-se na análise de tarefas, tal como constatado na produção internacional sobre o tema, as iniciativas de pesquisa de Ferreira (2009) e Ferreira et al. (2009) merecem destaque por terem avançado na análise organizacional, por meio de metodologia que permite a identificação de grandes temáticas de treinamento necessárias ao bom desempenho organizacional. Além do tratamento inédito da análise organizacional, outro avanço importante consistiu na adoção e na operacionalização do conceito de competência tanto para identificar necessidades no nível individual quanto nos níveis mais abrangentes (LIMA; BORGES-ANDRADE, 2006). 
Necessidades de treinamento organizacional e motivação para trabalhar

Diante do exposto, percebe-se que as pesquisas sobre ANT progrediram pouco nas últimas décadas, ainda que importantes aperfeiçoamentos tenham sido propostos. Sugestões de aplicação de conceitos e medidas de necessidade em diferentes níveis, principalmente no nível organizacional, não foram amplamente adotados em pesquisas da área. Ainda há carência de abordagens proativas em ANT, focadas no contexto e na estratégia organizacional. E saná-las exige conhecer o progresso das pesquisas sobre avaliação de efeitos de treinamento, subsistema no qual a produção, amplamente consolidada, permite a identificação de variáveis-chave a serem incorporadas à prática científica e profissional de ANT.

Entre essas variáveis, a literatura de avaliação de efeitos destaca, principalmente, características individuais da clientela e do ambiente de treinamento e de trabalho dos participantes. Como a presente pesquisa concentra-se no estudo da relação entre motivação para trabalhar e necessidades de treinamento, apenas a produção relativa à linha de pesquisa que trata da influência de variáveis da clientela sobre resultados de treinamento será aqui discutida. Neste cenário, especificamente características motivacionais são as que têm mostrado maior valor explicativo de aprendizagem e impacto de treinamentos, como afirmam Salas e Cannon-Bowers (2001).

Vários estudos têm fornecido evidências corroborando a concepção de que a motivação do treinando apresenta efeitos sobre a aquisição, a retenção e a aplicação, no trabalho, dos conhecimentos e habilidades adquiridos em treinamento. Entre tais evidências, destaca-se a meta-análise conduzida por Colquitt et al. (2000), cujos resultados apontam para um relacionamento positivo robusto entre motivação para aprender, definida como o desejo dos treinandos de assimilar os conteúdos do treinamento, e resultados de aprendizagem.

No contexto brasileiro, Lacerda (2002) relatou que uma medida de instrumentalidade (avaliação do indivíduo de que seu comportamento levaria ao alcance dos resultados esperados) apresentou-se como preditora de impacto do treinamento no trabalho em longo prazo. Lacerda e Abbad (2003) também encontraram resultados que destacam a importância da motivação para aprender na aplicação de conhecimentos adquiridos em programas de treinamentos presenciais.

Ciente de que os resultados de treinamento estão relacionados à mudança de comportamento do indivíduo no trabalho e que, portanto, se relacionam com seu desempenho, as conclusões de todos esses estudos de que motivação se correlaciona positivamente com resultados de treinamento reforçam a importância de se considerar a motivação na avaliação 
de desempenho. Com base nestas conclusões, Queiroga (2009) testou a hipótese de que o grau de motivação para trabalhar dos funcionários pesquisados estaria positivamente relacionado com o desempenho do indivíduo no trabalho (autorrelatos e indicadores organizacionais). Em ambas as organizações públicas pesquisadas pela autora, as autopercepções de desempenho dos servidores apresentaram correlações positivas e significativas com os três componentes da motivação para trabalhar, isolados (valência, instrumentalidade e expectativa) e combinados (fator geral da motivação).

Em suporte aos resultados obtidos por Queiroga (2009), Campbell (1990) afirma que a motivação é um determinante direto do desempenho. Ainda, Parker e Turner (2002) ressaltam a influência direta que as características individuais exercem sobre o desempenho no trabalho, com destaque para os aspectos motivacionais e cognitivos. As autoras apontam que as pessoas apresentarão melhores desempenhos se o trabalho for significativo para elas (o indivíduo atribuir alto valor de motivação ao trabalho) e satisfazer suas necessidades de crescimento.

Assim, se a área de avaliação de efeitos já comprovou que aprendizagem e transferência de treinamento são preditas por motivação, entre outros aspectos, e que motivação determina desempenho, não há razão para negligenciar tais variáveis nos estudos sobre necessidades de treinamento, que nada mais são do que medidas de desempenho. Como informado, este é justamente o propósito central da pesquisa sob análise. Anteriormente à exposição dos resultados obtidos, contudo, faz-se necessário explicar o processo de operacionalização metodológica ora empregado.

\section{MÉTODO DE PESQUISA}

Para facilitar a condução e a exposição dos procedimentos e técnicas empregados, a pesquisa foi dividida em três etapas preliminares: na primeira buscou-se elaborar e validar, semântica e estatisticamente, instrumento para aferição de necessidades de treinamento: na segunda etapa, procedeu-se à adaptação e validação estatística do questionário de motivação para o trabalho, originalmente proposto por Queiroga (2009); por fim, a terceira etapa tratou da formação de grupos de comparação em função de diferenças estatisticamente significativas no nível de motivação para trabalhar e da identificação de covariáveis para testagem isolada, conforme enunciado no objetivo geral exposto na introdução deste relato teórico-empírico, da relação entre motivação para o trabalho e necessidades de treinamento.

Para consecução da primeira etapa, efetuou-se pesquisa de documentos internos e externos à organização consultada, a fim de localizar conjunto de CHAs comum à maioria dos 
Necessidades de treinamento organizacional e motivação para trabalhar

postos de trabalho ocupados por servidores. Esta decisão de enfocar atributos demandados da maioria dos funcionários da organização deu-se pelo fato de a Autarquia contar com menos de 500 servidores efetivos e com atividades bastante distintas. Se somente os servidores lotados em duas diretorias, por exemplo, fossem amostrados, além de limitar o leque dos procedimentos analíticos optados (riscos à validade interna), os resultados dificilmente poderiam ser extrapolados para a realidade das demais unidades administrativas (riscos à validade externa). Neste sentido, consultou-se o produto do mapeamento de competências que estava sendo realizado à época na organização pesquisada.

Com o conhecimento das capacidades requeridas na maioria dos postos de trabalho, foi possível avançar para o segundo passo do método de elaboração do instrumento de necessidades de treinamento. Foram então formuladas descrições de competências, da forma mais genérica possível, com base nos CHAs mapeados em três categorias identificadas como adequadas para compor o questionário: leis e regulamentos; normas e procedimentos internos; e visão sistêmica. Para a busca de mais descrições de atribuições nessas categorias, analisouse o site institucional, a Intranet, o Relatório Anual de Atividades e o Regimento Interno da Autarquia. Todas as descrições pertinentes foram selecionadas e depois filtradas para restar somente aquelas capacidades comuns a todos os servidores. As descrições de competências redundantes foram contadas somente uma vez.

Como o Regimento Interno analisado era de 2006 e o mapeamento de competências analisado ainda não tinha sido concluído, em 2009, muitas atribuições desempenhadas no momento da pesquisa poderiam estar sendo ignoradas. Por isso, foi necessário acrescentar uma segunda fase a esta pesquisa documental. Assim, foram feitos contatos com a área de Desenvolvimento de Pessoal de outros órgãos públicos solicitando qualquer documento que descrevesse as competências e atribuições de servidores. Foi feita ainda uma pesquisa na Internet em busca das competências mais requisitadas de servidores públicos nas áreas de conhecimento antes especificadas.

As descrições de competências propostas com base nos documentos analisados, foram, em um segundo momento, apresentadas a um grupo de participantes com o objetivo de reunir mais capacidades comuns aos servidores, julgar a pertinência daquelas obtidas nas etapas anteriores e proceder à primeira rodada da validação semântica dos descritores de necessidades em construção. Este grupo focal foi constituído, em parceria com profissionais de TD\&E da Autarquia, por sete servidores intencionalmente selecionados, com pelo menos ensino superior completo e lotados em unidades diferentes da organização, nas quais eram 
reconhecidos pelo conhecimento elevado sobre as atividades ali desenvolvidas. O produto da aplicação deste grupo focal, conforme apresentado em seção oportuna, inclui apenas descritores de necessidades relacionadas à visão sistêmica. As demais áreas foram excluídas, pois, na visão dos participantes deste grupo, não eram aplicáveis a todas as unidades organizacionais.

Complementados os descritores e concluída a rodada inicial da validação semântica do instrumento de avaliação de necessidades de treinamento, foi possível dar seguimento à pesquisa com a validação por juízes do questionário de ANT. Dessa forma, com o intuito de aferir se os conteúdos do instrumento eram compreensíveis, conforme sugestão de Pasquali (1999), nova e definitiva rodada de validação semântica foi cumprida, por email, com membros da população delimitada nesta investigação.

Já para aferir a representatividade e confiabilidade dos comportamentos descritos em relação às categorias de complexidade, conforme argumentos de Bloom et al. (1972), foi realizada uma validação com cinco juízes especializados nas temáticas de ANT e de TD\&E, também virtualmente. Como na primeira rodada três descrições de competências não atingiram a taxa mínima de $60 \%$ de concordância interjuízes, e excluí-las ou mudá-las de categoria prejudicaria a divisão homogênea entre os níveis da taxonomia, uma segunda fase foi realizada. Desta vez, os juízes foram orientados a apresentar sugestões de descritores compatíveis com os níveis de aprendizagem usados como âncora na construção do instrumento.

Por fim, com vistas à efetuação da validação empírica do instrumento de necessidades de treinamento em visão sistêmica, procedeu-se à coleta final das opiniões dos participantes ao questionário teoricamente validado, cujos 18 itens foram então associados a duas escalas de julgamento - uma de domínio e outra de importância dos CHAs descritos, ambas do tipo Likert de quatro pontos. Como este instrumento foi aplicado nos servidores juntamente com o questionário de motivação para trabalhar, ressalta-se que o mesmo procedimento de coleta de dados ora relatado, assim como as configurações amostrais, foi utilizado para as etapas 2 e 3 . Portanto, tais descrições procedimentais não serão apresentadas adiante no momento da exposição metodológica relativa às etapas subsequentes.

A coleta de dados por meio desses dois instrumentos foi realizada, então, via Internet. No mesmo dia em que os questionários foram enviados para o email institucional de todos os servidores, o Presidente da Autarquia enviou uma mensagem de apoio à pesquisa, na qual ressaltava a importância da participação de todos. Além disso, o link de acesso ao 
Necessidades de treinamento organizacional e motivação para trabalhar

questionário foi disponibilizado no Mural do Servidor, na Intranet, para que o maior número de participação fosse alcançado. O questionário ficou disponível on line por 25 dias e, ao final deste período, obteve-se uma taxa de retorno de 45.32\% (213 respondentes), sendo que o maior fluxo $(33.83 \%)$ de participação foi observado nos primeiros quatro dias de pesquisa.

A amostra final usada, então, para validação do instrumento de necessidades (etapa 1), validação do instrumento de motivação para trabalhar (etapa 2), constituição dos grupos de comparação em função da força motivacional e seleção das covariáveis para composição do modelo final de investigação (etapa 3), bem como para o teste da relação entre as variáveis implicadas nesta pesquisa (objetivo geral), foi formada, em função da população de 470 servidores da Autarquia, pelos 213 servidores que se dispuseram a responder aos questionários. A maioria da amostra, vale ressaltar: tem menos de 35 anos (48.4\%); é do sexo masculino (54.9\%); concluiu pelo menos o ensino superior (77\%); trabalha há menos de 2 anos na Autarquia (53,1\%); está lotada na Diretoria Financeira (30\%) ou na Diretoria de Administração e Tecnologia (23\%); e não tem cargo comissionado ou função gratificada $(74.7 \%)$.

Antes de executar os procedimentos exigidos para validação empírica dos instrumentos usados nesta pesquisa, bem como os testes de relacionamento entre as variáveisalvo da pesquisa, previstos no objetivo geral, foram realizadas, mediante uso do pacote estatístico SPSS (Statistical Package for Social Science), versão 17.0, análises descritivas e exploratórias conforme orientações de Tabachnick e Fidell (2001). Com o arquivo de dados finalmente composto, calculou-se o Índice de Prioridade de Treinamento - IPT, consoante fórmula adaptada de Borges-Andrade e Lima (1983), que determina uma necessidade de treinamento em função de respostas que apontem, concomitantemente, nenhum ou pouco domínio e total ou muita importância de cada competência apresentada no questionário referente.

Calculadas as necessidades de treinamento dos servidores amostrados, no estudo 3, passou-se à formação dos grupos de comparação em função de diferenças estatisticamente significativas no nível de motivação para trabalhar, bem como à identificação de variáveis de controle estatístico (covariáveis) capazes de serem incluídas no modelo de investigação, a fim de reduzir as ameaças à validade interna da pesquisa, e à análise do relacionamento entre motivação para trabalhar e a complexidade das necessidades de treinamento, principal objetivo da presente pesquisa. 
Gisela Gomes da Silva \& Pedro Paulo Murce Meneses

Para tanto, com base nas subescalas validadas do instrumento de Motivação para Trabalhar, primeiramente, calculou-se a força motivacional (FM) dos respondentes. Conforme base teórica usada pelos proponentes originais do questionário - Teoria de Expectância de Vroom (1964), FM representa a quantidade de esforço ou pressão de uma pessoa para motivar-se. Do ponto de vista matemático, é o produto de conjuntos de itens que expressam a expectativa (percepção de quanto o esforço conduz aos resultados esperados), o valor instrumental (relação percebida entre certos procedimentos laborais e a obtenção dos resultados) e a valência (importância ou o valor que esse indivíduo atribui a cada uma dessas recompensas), elementos centrais da proposição teórica do referido autor.

Dessa maneira, a força motivacional de cada respondente foi calculada multiplicando a média das respostas de expectativa, instrumentalidade e valência. Como a escala de respostas variava entre os valores 0 a 4 , os produtos obtidos para FM poderiam situar-se entre 0 (nada motivado) e 64 (totalmente motivado para trabalhar). Em função dessa faixa de valores, foram formados dois grupos de comparação: o grupo 1 foi composto pelos servidores com reduzido grau de força motivacional $(0 \leq \mathrm{FM} \geq 32)$ e o grupo 2 , por respondentes com elevado grau de motivação para trabalhar $(32.01 \leq \mathrm{FM} \geq 64)$. Para testar a existência de uma diferença significativa entre as médias dos dois grupos foi realizado um Teste $t$ para amostras independentes.

Para a seleção das covariáveis, correlações bivariadas entre determinados dados sociodemográficos e destes com a variável dependente FM foram calculadas. Esses dados foram inicialmente escolhidos em função da possibilidade, ante desenho de pesquisa pouco robusto à interferência de variáveis externas à pesquisa, de afetarem a relação entre motivação para trabalhar e necessidades de treinamento. Por exemplo, caso um grupo de comparação, na média, reunisse participantes com menos tempo de serviço na organização estudada, este padrão poderia, por si só, explicar diferenças nos graus de necessidades de treinamento manifestos. Assim, se tal hipótese alternativa não fosse antes considerada, a ponto de a variável denominada de tempo de serviço ser submetida a algum tipo de controle estatístico, estaria dificultada a verificação da relação linear proposta ente motivação e necessidades.

Selecionadas as covariáveis, foi possível a realização de uma análise de covariância (ANCOVA) para testar o relacionamento entre a força motivacional do servidor e sua percepção de necessidades de treinamento pretendido no objetivo geral desta pesquisa. Em suma, diante do exposto até o momento, a análise de covariância foi realizada com base na formação de dois grupos de participantes que, controlada a influência da covariável 
Necessidades de treinamento organizacional e motivação para trabalhar

identificada para composição do modelo, foram comparados em relação à magnitude das necessidades de treinamento em visão sistêmica. Vale ressaltar que esta análise derradeira foi precedida pela investigação dos pressupostos de normalidade, homogeneidade de variância, linearidade e homogeneidade de regressão.

\section{RESULTADOS E DISCUSSÃO}

Na etapa 1, cuja meta consistia no desenvolvimento de um instrumento para aferição das necessidades de treinamento, a pesquisa documental interna, primeira etapa efetivada, resultou na localização de 23 competências relacionadas à legislação $(n=9)$, normas e procedimentos internos $(n=7)$ e visão sistêmica $(n=7)$, necessárias a todos os postos de trabalho dos servidores da Autarquia. Em seguida, por meio de consulta a documentos externos à organização estudada, foi possível acrescentar a esta relação inicial de competências mais quatro descrições sobre leis e regulamentos $(n=13)$, duas em normas e procedimentos internos $(n=9)$ e cinco em visão sistêmica $(n=12)$. Essas 34 descrições resultantes da pesquisa documental, na segunda fase desta etapa, foram tratadas no grupo de foco, cujo propósito visava à legitimação e à validação semântica inicial do conjunto de CHAs.

Neste momento, recorreu-se à consulta a servidores experientes, ou especialistas em conteúdo, conforme recomendações de pesquisadores da área (e.g., WEXLEY, 1984; LATHAM, 1988; AGUINIS; KRAIGER, 2009). À medida que todos os participantes do grupo de foco contribuíram com a exposição da visão sobre suas áreas para o julgamento das competências apresentadas, das 34 competências resultantes das análises documentais, nove sofreram reajustes, cinco foram criadas e quatro foram excluídas da relação inicialmente proposta. Vale destacar, portanto, a pertinência do procedimento de coleta de dados sugerido pelos autores supracitados.

Mas apesar dos resultados positivos deste segundo momento - condução do grupo de foco, constatou-se que a aplicação de leis e regulamentos variava muito entre as unidades administrativas da organização, o que dificultou a elaboração de descrições genéricas o suficiente para serem respondidas por todos os servidores da Autarquia. Além disso, mediante consulta à relação de treinamentos financiados pela organização até um ano e meio antes desta pesquisa, percebeu-se que a área de legislação havia sido bastante atendida por iniciativas de treinamento. Este fato, em um estudo correlacional naturalmente menos resistente a ameaças à validade interna, poderia interferir na emergência de necessidades de 


\section{Gisela Gomes da Silva \& Pedro Paulo Murce Meneses}

treinamento, dificultando a análise da relação entre esta variável e motivação para trabalhar. Optou-se, então, por não utilizar as competências relativas à legislação. Pela dificuldade de identificação de competências equitativamente distribuídas nos diferentes níveis de complexidade da aprendizagem, fato que poderia também intervir na emergência de necessidades de treinamento, decidiu-se ainda pela exclusão dos descritores relacionados a normas e procedimentos internos.

Restaram, dessa maneira, 15 descritores comportamentais pertinentes à visão sistêmica, pois, vale lembrar, das nove descrições relativas às três categorias de competências, ajustadas durante o grupo focal, apenas uma era relativa à visão sistêmica; das cinco criadas, três se enquadravam nesta categoria; e das quatro competências excluídas, nenhuma tratava de visão sistêmica. Considerando as informações colhidas nas análises documentais e no próprio grupo de foco, esse conjunto foi ampliado para 18 descritores, em função da necessidade de que cada nível de complexidade da aprendizagem (conhecimento, compreensão, aplicação, análise, síntese e avaliação), conforme taxonomia de Bloom et al. (1972), fosse proporcionalmente representado a fim de permitir, adiante, probabilidade idêntica de resposta dos participantes (Tabela 1).

Tabela 1. Descritores de competências em visão sistêmica validados semanticamente

\begin{tabular}{|c|c|}
\hline $\begin{array}{l}\text { Níveis de } \\
\text { Aprendizagem }\end{array}$ & Descritores comportamentais de CHAs \\
\hline Avaliação & $\begin{array}{l}\text { 1. Avaliar o ambiente interno (número de servidores, volume de trabalho, orçamento, etc.) e } \\
\text { externo (cenários político, financeiro, ambiental, etc.) à Autarquia a fim de contribuir para a } \\
\text { tomada de decisões } \\
\text { 2. Avaliar a situação atual da Autarquia levando em consideração experiências passadas } \\
\text { 3. Julgar a relevância das informações do ambiente interno (número de servidores, volume de } \\
\text { trabalho, orçamento, etc.) e externo (cenários político, financeiro, ambiental, etc.) para o bom } \\
\text { desempenho da Autarquia como um todo }\end{array}$ \\
\hline & $\begin{array}{l}\text { 4. Propor soluções de trabalho que articulem tanto aspetos do ambiente externo quanto interno } \\
\text { à Autarquia }\end{array}$ \\
\hline Síntese & Estabelecer ações que favoreçam a integração das atividades entre as unidades da Autarquia \\
\hline & Projetar atividades de intercâmbio de experiências (benchmarking) com outras entidades \\
\hline & $\begin{array}{l}\text { Distinguir a influência de aspectos do ambiente interno à Autarquia no cumprimento de suas } \\
\text { atividades }\end{array}$ \\
\hline Análise & $\begin{array}{l}\text { 8. Distinguir a influência de aspectos do ambiente externo no cumprimento de suas atividades } \\
\text { 9. Ordenar, quanto à prioridade, as atividades de sua unidade em função das metas da } \\
\text { Autarquia }\end{array}$ \\
\hline Aplicação & $\begin{array}{l}\text { 10. Realizar ações alinhadas aos objetivos estratégicos da Autarquia } \\
\text { 11. Utilizar informações de outras áreas da Autarquia em suas atividades } \\
\text { 12. Empregar experiências bem-sucedidas de outras unidades ou entidades na execução de suas } \\
\text { atividades }\end{array}$ \\
\hline
\end{tabular}


Necessidades de treinamento organizacional e motivação para trabalhar

13. Explicar as contribuições de cada unidade administrativa para o alcance dos objetivos institucionais da Autarquia

Compreensão 14. Descrever as relações de interdependência, ante os objetivos institucionais, entre as unidades administrativas da Autarquia

15. Listar as principais instituições potencialmente capazes de influenciar o funcionamento da Autarquia

16. Identificar a relação de hierarquia entre as unidades da Autarquia

17. Explicar o fluxo de trabalho da unidade onde você trabalha

18. Descrever os direcionadores estratégicos da Autarquia: missão, visão, objetivos etc. Fonte: autores

Novamente, ressalta-se que o uso da taxonomia no processo de identificação e descrição de necessidades de treinamento em visão sistêmica deveu-se à exigência de que os participantes, quando da participação na aplicação dos questionários finalmente propostos, tivessem a mesma oportunidade de selecionar um ou outro descritor, independentemente do grau de complexidade inerente. Além disso, como asseveram Abbad e Borges-Andrade (2004), as taxonomias de resultados educacionais são ótimos exemplos de conhecimentos técnicos que facilitam o planejamento, a execução e a avaliação de ações voltadas à aprendizagem em situações e ambientes diversos. Portanto, descrever indicadores de necessidades de treinamento utilizando a mesma composição básica de objetivos instrucionais pode ser uma das formas de se integrar todos os subsistemas de TD\&E e estes com as demais funções da área de gestão de pessoas. Integração esta tão importante para o avanço da área de treinamento como um todo (ABBAD, 1999).

Com a conclusão do grupo de foco, iniciou-se nova e definitiva rodada de validação semântica com o envio de emails, pedidos de colaboração por telefone e contatos pessoais. Somente sete servidores se dispuseram a participar desta fase da etapa 1 e apenas dois sugeriram alterações na redação dos descritores, então acatadas. Em seguida, passou-se à análise por juízes, segundo momento que, agregada à análise semântica, integrou o processo de validação teórica do instrumento de necessidades de treinamento sobre visão sistêmica. Nas duas rodadas desta análise por juízes, dois descritores foram classificados em níveis de aprendizagem diferentes dos inicialmente atribuídos, e outros três descritores tiveram suas redações alteradas para que pudessem se adequar à categorização de complexidade previamente definida. Mesmo com as mudanças propostas, manteve-se a distribuição equitativa de três descritores por nível de aprendizagem.

Nesta etapa de validação teórica dos descritores, como observado, além dos servidores experientes no conteúdo das atividades desenvolvidas, também foram consultados especialistas em taxonomias de aprendizagem e em ANT. Apesar da morosidade deste processo, a sequência de passos sugerida por Lima e Borges-Andrade (2006) e as validações

REAd I Porto Alegre - Edição 71 - N 1 - janeiro/abril 2012 - p. 27-62 
Gisela Gomes da Silva \& Pedro Paulo Murce Meneses

teóricas se mostraram adequadas e imprescindíveis ao alcance de descritores precisos e confiáveis de necessidades sobre visão sistêmica. Teoricamente validado o instrumento de ANT, passou-se à validação empírica, última fase do processo de desenvolvimento do instrumento citado.

Primeiramente, constatou-se que a matriz dos índices de prioridade, o Kaiser-MeyerOlkin - KMO, o índice do teste de esfericidade de Bartlett, o determinante, a matriz antiimagem e os valores das comunalidades apontaram a adequação de se realizar a fatoração da matriz, de acordo com Tabachnick e Fidell (2001). Em seguida, para a extração inicial da matriz de componentes, foi realizada a análise dos componentes principais, cujos resultados demonstraram apenas dois valores próprios (eigenvalues) maiores do que um, sendo a variância total explicada pelo primeiro deles igual a $52.83 \%$ e pelo segundo de apenas $6.34 \%$. Apesar da pequena variância explicada por este último componente, a fim de se evitar uma decisão equivocada do ponto de vista estatístico, a análise fatorial dos eixos principais foi realizada, inicialmente, com a determinação prévia de extração de dois fatores.

Como o índice de correlação entre esses dois fatores alcançou o valor de 0.77 $(p<0.01)$, o que tornaria difícil, e talvez inoportuna, a interpretação teórica do resultado, optou-se pela extração final de solução unifatorial, como já havia sido identificado quando da realização da análise dos componentes principais. Dessa forma, uma nova e definitiva análise fatorial dos eixos principais foi feita com apenas um fator. As cargas fatoriais variaram entre 0.39 e 0.83 . A variância total explicada foi de $52.83 \%$ e o eigenvalue alcançou o índice de 9.51. Também foi feita uma análise de consistência do fator, por meio do cálculo do Alfa de Cronbach, que resultou em um valor de 0.94 para os 18 itens do questionário de ANT, considerado um excelente resultado do ponto de vista da confiabilidade.

Finalizada a validação empírica do instrumento de necessidades de treinamento sobre visão sistêmica e, portanto, a etapa 1 , passou-se à execução da etapa 2 , cujo objetivo, vale relembrar, consistia na validação estatística do questionário de motivação para trabalhar originalmente elaborado por Queiroga (2009). Composto por 12 itens relacionados à valência, 12 à instrumentalidade e oito à expectativa, conforme orientação teórica adotada de Vroom (1964), o instrumento foi submetido aos mesmos procedimentos estatísticos aplicados no caso do questionário de necessidades de treinamento anteriormente exposto. Assim, para a extração inicial dos fatores, foi realizada a análise dos principais componentes para cada subescala. Os resultados obtidos foram bem semelhantes àqueles encontrados pela proponente do questionário, sugerindo uma estrutura unifatorial para cada uma das três subescalas. 
Necessidades de treinamento organizacional e motivação para trabalhar

Dessa forma, a análise fatorial dos eixos principais foi realizada com critério de extração de um fator apenas para cada subescala. Os eingenvalues das escalas de valência, instrumentalidade e expectativa foram, respectivamente, 4.69, 7.35 e 4.96. Já os percentuais da variância total explicada alcançaram os valores de 41.3, 61.2 e 62. Os índices de confiabilidade obtidos foram de 0.86, 0.94 e 0.91, indicando que as subescalas eram internamente consistentes. Além disso, as cargas fatoriais em todas as subescalas variaram de 0.42 a 0.88 , evidenciando um alto grau de representatividade dos itens em relação à dimensão teórica que lhes deu origem. Validado empiricamente este instrumento, passou-se, por fim, ao cumprimento do objetivo maior desta pesquisa, que consistia no teste da relação entre motivação para trabalhar e necessidades de treinamento.

Para que pudessem ser formados os grupos de comparação, tal como exigia o desenho de pesquisa selecionado na etapa de delineamento metodológico, foi preciso, antes, calcular a força motivacional de cada participante, com base nas respostas de cada um deles às escalas de valência, instrumentalidade e expectativa. Para tanto, os respondentes foram divididos em dois grupos de comparação: 1 - servidores menos motivados (Força Motivacional $\leq 32$ ); e grupo 2 - servidores mais motivados para trabalhar (FM>32). Tal divisão foi estatisticamente confirmada pela aplicação de um teste estatístico de diferença entre médias (Teste- $t$ para amostras independentes), cujos resultados evidenciaram uma diferença entre os grupos de $t=-$ $19.76(\operatorname{com} p<0.01)$.

Confirmada a diferença em relação à força motivacional dos dois grupos de comparação, era preciso, ainda, determinar as covariáveis que seriam incluídas no modelo estatístico de investigação da relação entre motivação e necessidades de treinamento. Para tanto, fez-se necessário, em função das respostas dos participantes às escalas de julgamento de domínio e importância associadas a cada um dos 18 itens do questionário, calcular os Índices de Prioridade de Treinamento relativos aos descritores comportamentais de visão sistêmica. Como ambas as escalas continham apenas quatro opções de resposta, e considerando a fórmula usada para o cálculo dos IPTs, os resultados poderiam variar apenas entre o valor zero e 16.

Entretanto, em função de respostas concentradas nos pontos mais baixos das escalas, o resultado da composição desta variável dependente indicou prioridades entre 3.95 e 5.92, com desvios-padrão oscilando entre 2.87 e 4.24. Colocado de outra maneira, a necessidade de desenvolvimento de competências relativas à visão sistêmica não se mostrou tão prioritária quanto se imaginava e, mais importante, ante os procedimentos estatísticos delimitados, não 
houve discrepância significativa de necessidade de treinamento entre os diferentes níveis de complexidade a que foram associados os descritores comportamentais.

É importante mencionar alguns fatores que podem explicar a baixa percepção de necessidade de treinamento em visão sistêmica. Primeiramente, constatou-se, na coleta de dados integrante da pesquisa documental executada, a ausência de um planejamento estratégico atualizado na organização. Talvez por isso os servidores não tenham compreendido a importância de se pensar sistemicamente, buscando integrar, ainda que apenas cognitivamente, as atividades das áreas. Além disso, a estrutura da Autarquia é classicamente departamentalizada e, portanto, altamente verticalizada, o que pode ter gerado uma percepção de completa independência dos respondentes em relação às atividades das demais unidades organizacionais e, assim, a perda da visão da organização como um todo (CURY, 2000).

Outro motivo para a baixa percepção de necessidades de treinamento pode ter sido a aversão à mudança. A possibilidade de participar de ações de TD\&E e ter de colocar em prática o aprendizado sobre visão sistêmica, acarretando mudanças nos processos organizacionais, pode ter gerado receio nos respondentes em manifestar necessidades de treinamento compatíveis com a realidade da Autarquia. Gondim et al. (2006) apontam que há resistência à mudança organizacional por parte dos trabalhadores quanto esses se vêem obrigados a modificar rotinas e procedimentos de realização de tarefas e atividades, contrariando, em algumas circunstâncias, sua experiência profissional acumulada.

Essa resistência pode ser ainda mais intensa em servidores públicos. Resquícios do sistema clientelista e burocrático da Administração Pública brasileira geram sentimentos de desestímulo, de estabilidade e de aversão a mudanças, que, aliados à isonomia salarial e à falta de preocupação com os resultados, caracterizam a maior parte das organizações, em particular as organizações públicas (CARBONE, 1995). Destaca-se que, mesmo com os avanços estimulados, na década de 1990, pelo Programa de Qualidade e Produtividade na Administração Pública, até a oficialização, em 2005, do Programa Nacional de Gestão Pública e Desburocratização, o setor público brasileiro ainda padece de problemas crônicos, como a supervalorização de estruturas amplamente rígidas e verticalizadas (BATISTA, 1999) que, associadas ao apego às normas e ao poder e ao paternalismo nas relações profissionais, impede a adoção de modelos de gestão mais eficientes, inclusive de recursos humanos (PIRES; MACÊDO, 2006). 
Necessidades de treinamento organizacional e motivação para trabalhar

Bresser-Pereira (1996) há aproximadamente duas décadas já havia previsto que a reforma da administração pública, estimulada no cenário brasileiro, na década de 1990, em função dos resultados obtidos pelos países membro da Organização para a Cooperação e Desenvolvimento Econômico (OCDE), no âmbito da gestão, seria mais difícil do que nas dimensões cultural e institucional-legal. De fato, sobretudo nesta última perspectiva, nota-se uma série de novas orientações mais bem associadas a um modelo estratégico de gestão de pessoas. Tal constatação se torna evidente nos recentes decretos, regidos pelo Ministério do Planejamento, Orçamento e Gestão (MP), cujo teor denota uma iniciativa de conferir um caráter estratégico à administração de pessoal, tipicamente caracterizada no Brasil como um setor de baixa autonomia, operante apenas sob um aspecto legal e operacional (MARCONI, 2003).

Retomando a descrição dos resultados obtidos, independentemente dos IPTs compostos na formação final da variável dependente, cujas implicações sobre os resultados estatísticos obtidos serão discutidas adiante, prosseguiu-se com a execução da pesquisa. Assim, o próximo passo, conforme mencionado anteriormente, consistiu na seleção das covariáveis para proposição do modelo estatístico final de investigação da relação entre motivação e necessidades de treinamento. Para tanto, foram calculadas correlações bivariadas entre dados sociodemográficos e funcionais, que poderiam, ante uma composição nãoaleatória dos grupos de comparação, interferir na relação pretendida entre motivação e necessidades, e entre esses dados e a variável dependente selecionada - necessidades de treinamento em visão sistêmica.

Neste ínterim, a única covariável selecionada foi tempo de trabalho, correlacionada inversa e significativamente com a variável dependente $(r=0.32$; com $p<0.001)$. Este resultado intermediário, de certa forma, corroborou os achados de Magalhães e Borges-Andrade (2001) em pesquisa realizada na Caixa Econômica Federal, na qual tempo de trabalho na organização emergiu como a melhor variável preditora de necessidades de treinamento (se maior o tempo de serviço, então menores as necessidades de treinamento).

Formados os grupos de comparação em função da força motivacional dos participantes amostrados, constituída a variável dependente com base nos Índices de Prioridade de Treinamento e selecionada a covariável para inclusão no modelo investigativo, iniciou-se o teste principal desta pesquisa, qual seja, da relação entre motivação para trabalhar e necessidades de treinamento em visão sistêmica. Anteriormente, entretanto, foram verificados os pressupostos exigidos pela análise de covariância, tal como informado na seção 
Gisela Gomes da Silva \& Pedro Paulo Murce Meneses

metodológica. Como primeiro produto da análise de covariância, a Tabela 2 apresenta os valores das médias e dos desvios-padrão, para cada grupo de comparação, dos escores na variável dependente anterior e posteriormente aos ajustes efetuados com o uso da covariável selecionada.

Tabela 2. Médias e desvios-padrão antes e após ajustes pela covariável

\begin{tabular}{ccccccc}
\hline \multirow{2}{*}{ Grupos de Comparação } & Média & $\begin{array}{c}\text { Desvio- } \\
\text { Padrão }\end{array}$ & Média & Erro-Padrão & $\begin{array}{c}\text { Limite } \\
\text { Inferior }\end{array}$ & $\begin{array}{c}\text { Limite } \\
\text { Superior }\end{array}$ \\
\cline { 2 - 7 } & $-0,01$ & 0,90 & $-0,07$ & 0,08 & $-0,23$ & 0,09 \\
\hline $\begin{array}{c}\text { Força Motivacional } \\
\text { Reduzida }\end{array}$ & 0,02 & 1,09 & 0,11 & 0,10 & $-0,10$ & 0,31 \\
$\begin{array}{c}\text { Força Motivacional } \\
\text { Elevada }\end{array}$ & & & & & & \\
\hline
\end{tabular}

Fonte: autores

Os resultados, após ajustados pela covariável, indicaram que o grupo dos servidores com força motivacional elevada apresentou maiores necessidades de treinamento do que o grupo com força motivacional reduzida. Apesar deste indício, os limites inferiores e superiores atribuídos a cada grupo de comparação se sobrepuseram em grande parte, apontando para uma possível ausência de relação entre motivação para trabalhar e necessidades de treinamento em visão sistêmica. Nesse sentido, a fim de que tais diferenças fossem investigadas mais precisamente, os resultados gerados pela análise de covariância foram identificados (Tabela 3).

Tabela 3. Resultados da análise de covariância

\begin{tabular}{lcccccc}
\hline \multicolumn{1}{c}{ Fonte } & $\begin{array}{c}\text { Soma dos } \\
\text { Quadrados }\end{array}$ & $\begin{array}{c}\text { Graus de } \\
\text { Liberdade }\end{array}$ & $\begin{array}{c}\text { Média dos } \\
\text { Quadrados }\end{array}$ & F & Sig. & $\eta^{2}$ \\
\hline Modelo Corrigido & $21,79^{\mathrm{a}}$ & 2 & 10,89 & 12,69 & 0,00 & 0,11 \\
Intercepto & 11,07 & 1 & 11,07 & 12,90 & 0,00 & 0,06 \\
Tempo de Trabalho & 21,74 & 1 & 21,74 & 25,32 & 0,00 & 0,11 \\
Grupos de Comparação & 1,46 & 1 & 1,46 & 1,70 & 0,19 & 0,01 \\
Erro & 180,27 & 210 & 0,86 & & & \\
Total & 202,06 & 213 & & & & \\
Total Corrigido & 202,06 & 212 & & & & \\
\hline
\end{tabular}

$\mathrm{R}^{2}=0,11\left(\mathrm{R}^{2}\right.$ ajustado $\left.=0,10\right)$

Fonte: autores

Conforme observado, os resultados da análise de covariância não confirmaram as diferenças observadas entre as médias ajustadas obtidas pelos dois grupos de comparação na variável dependente. Ante o valor de $\mathrm{F}(2,210)=1.7$ e o nível de significância obtido ( $p=$ 0.19), não se pode afirmar que o grupo com motivação elevada para o trabalho (Grupo 2) percebeu mais necessidades de treinamento do que o grupo com força motivacional reduzida (Grupo 1). De fato, a variação na percepção de necessidades de treinamento $\left(\mathrm{R}^{2}\right.$ ajustado = REAd I Porto Alegre - Edição 71 - N 1 - janeiro/abril 2012 - p. 27-62 
Necessidades de treinamento organizacional e motivação para trabalhar

0.10) pode ser creditada à covariável tempo de trabalho, mas não, como indica a magnitude da relação obtida $\left(\eta^{2}=0.01\right)$, à força motivacional dos servidores.

Apesar de os servidores com menos tempo de trabalho terem apresentado mais necessidades de treinamento, motivação para trabalhar não se correlacionou com necessidades de treinamento, podendo-se inferir, assim, que os servidores novatos não são, necessariamente, os mais motivados para trabalhar na autarquia consultada. Especulava-se que os servidores com pouco tempo de serviço prestado à organização seriam os mais motivados para trabalhar e apresentariam necessidades de treinamento mais complexas. De fato, a relação positiva entre motivação e complexidade de necessidades de treinamento sequer foi formalmente testada. Deduziu-se, mediante os resultados da análise de covariância, que não indicaram diferenças nos níveis de necessidade em função dos graus de motivação dos grupos constituídos, que também não haveria relação entre motivação e complexidade das necessidades. Além disso, em função da reduzida dispersão dos IPTs na faixa de valores préestabelecida (entre 0 e 16), não havia condição inicial para a realização dessa testagem.

Como os novatos demonstraram mais necessidades de treinamento, mas não, necessariamente, mais motivação, logicamente, necessidades e motivação não se correlacionaram. Entendendo necessidades de treinamento como problemas de desempenho, conforme teoria de Gilbert (1978) e Mager e Pipe (1984), a ausência de correlação encontrada nesta pesquisa vai de encontro aos resultados da maioria das pesquisas sobre motivação e desempenho (e.g., CAMPBELL, 1990; PARKER; TURNER, 2002). De qualquer forma, é importante destacar que alguns outros estudos também não evidenciaram tal relação de predição, e por isso merecem aqui atenção especial.

Ribeiro (2005), por exemplo, cita uma pesquisa na qual os resultados demonstraram que a motivação pré-treinamento influenciava a motivação para transferir o aprendido, mas a predição da transferência em si, ou seja, a mudança de comportamento, não foi confirmada. Esta mesma autora, pesquisando organizações públicas e privadas, ressalta que os participantes provenientes daquelas tendem a perceber pouca utilidade de novas aprendizagens no trabalho como meio útil à obtenção de resultados valorizados. Sallorenzo (2000) encontrou que à medida que o treinado distancia-se do final do evento instrucional, seu comportamento passa a ser cada vez mais controlado pelo ambiente de trabalho e não por sua motivação. Na pesquisa realizada por Queiroga (2009), o grau de motivação para trabalhar dos funcionários públicos não se correlacionou com os resultados das avaliações de desempenho realizadas pelos chefes. 
Gisela Gomes da Silva \& Pedro Paulo Murce Meneses

Apesar de estas pesquisas também não terem indicado correlação entre motivação e desempenho, somente outros resultados prioritários foram discutidos. Assim, como não há na literatura científica nacional e internacional de TD\&E resultados acerca desta relação entre motivação para trabalhar e necessidades de treinamento para serem confrontados aos resultados desta pesquisa, tentar-se-á refletir sobre algumas possibilidades que levaram ao resultado evidenciado.

Primeiramente, os resultados antes apontados são de suma importância, ainda que contraditórios, para a orientação de modelagens futuras de pesquisas na área de ANT. É consenso na literatura atual de TD\&E (MENESES; ZERBINI; ABBAD, 2010), e também em outras áreas funcionais da gestão de recursos humanos, que o desempenho humano no trabalho é fator de três elementos - capacidades, então integradas por repertórios de conhecimentos, habilidades e atitudes; condições, que abarcam fatores ambientais, sobretudo em termos psicossociais, materiais e técnicos; e motivação, neste estudo, significada conforme teoria de expectância (VROOM, 1964), que a define como produto da atração em relação a determinado objeto (valência), do conhecimento das estratégias de aproximação do objeto visado (instrumentalidade) e da antevisão sobre as consequências associadas ao contato com o objeto desejado (expectância).

O presente estudo buscou testar a relação direta entre motivação para o trabalho, então caracterizado como preditor direto de desempenho, e, consequentemente, a de necessidade de treinamento. Entretanto, os resultados da pesquisa, e também uma reflexão teórica mais aprofundada sobre os fatores determinantes do desempenho, não apontaram para a direção vislumbrada. Isso talvez reforce a hipótese de que motivação não pode ser enquadrada, em modelos de investigação desta natureza, como preditor direto de desempenho ou, mais especificamente, de necessidades de treinamento. Como colocam as teorias motivacionais de processo, categoria que contempla a teoria antes referida, a motivação é produto ambiental, dependente, portanto, da forma como as condições de trabalho são gerenciadas. Desta forma, uma importante contribuição deste estudo implica em apontar que modelos futuros de pesquisa considerem a motivação, conforme atestam resultados de pesquisa na área de avaliação de efeitos de treinamento, como variável mediadora ou moderadora, ou mesmo de controle estatístico em desenhos, da relação entre condições de trabalho e desempenho humano, e não como preditora direta deste.

Além disso, é importante destacar a suposição de que os servidores novatos seriam mais motivados do que os veteranos, buscariam um melhor desempenho no trabalho e, por 
Necessidades de treinamento organizacional e motivação para trabalhar

isso, teriam necessidades mais complexas de treinamento. Tal especulação foi feita considerando que, por ainda terem possibilidade de crescimento (como, por exemplo, ocupar uma função gratificada ou um cargo de chefia) na organização e estarem em estágio probatório, os servidores com pouco tempo de serviço seriam incentivados a apresentar um melhor desempenho. Segundo Parker e Turner (2002), se o indivíduo perceber a possibilidade de o trabalho satisfazer suas necessidades de crescimento, ele atribuirá alta valência ao trabalho e apresentará um melhor desempenho, em função das consequências que associou à emissão de um bom desempenho. Os resultados da subescala de expectativa demonstraram que os servidores consideram praticamente provável (em uma escala de 0 a 4 , sendo $0=$ nada provável e 4=muito provável, a média foi de 2,64) que seu trabalho lhe trouxesse crescimento profissional. Entretanto, os desvios-padrão associados aos itens de tal quesito indicaram que este resultado médio não refletiu precisamente o comportamento de todos os servidores amostrados, de forma que, para alguns desses, era nada ou pouco provável que seu trabalho lhe proporcionasse crescimento.

Em relação ao estágio probatório, como previsto em lei, durante os três primeiros anos no cargo público, o servidor tem seu desempenho avaliado periodicamente pela chefia imediata, e se o desempenho não for satisfatório, o servidor deve ser demitido do cargo público; ao contrário daqueles que já foram aprovados no estágio probatório, que antes de perderem o cargo, por algum motivo, têm direito à defesa em um processo administrativo disciplinar. Assim, esperava-se que, por ter o desempenho avaliado mais vezes do que o dos servidores já aprovados no estágio probatório, os novatos se motivariam mais e buscariam desenvolver competências mais complexas para apresentar melhores resultados.

De acordo com Vroom (1964), se o indivíduo atribuir valor positivo aos resultados de sua ação, bem como às expectativas que ele possui de que, agindo de certo modo, obterá as consequências que espera, então terá alto nível de motivação. Esperava-se, portanto, que os novatos atribuíssem valor positivo a obter bons resultados nas avaliações de desempenho e, consequentemente, a serem aprovados no estágio probatório, aumentando seu grau de motivação para o trabalho. Talvez os servidores não considerem o estágio probatório um período tão importante, por, na prática, a avaliação geralmente não ser tão rigorosa quanto deveria.

É importante mencionar, nesse ínterim, que se encontra em curso na administração pública federal um movimento de posicionamento estratégico das políticas e funções de recursos humanos. Evidências concretas dessas iniciativas podem ser conferidas nos recentes 
decretos editados pelo MP, como mencionado antes. Especificamente, o último desses documentos, o de número 7.133, publicado pela Casa Civil em 2010, trata da avaliação de desempenho humano e institucional de maneira vinculada; as metas individuais de desempenho deverão, deste ponto em diante, ser vinculadas a metas setoriais e institucionais. E mais importante, além das metas de desempenho, determinados comportamentos também passam a ser objeto de uma avaliação no esquema $360^{\circ}$, quais sejam a qualidade técnica do trabalho, a capacidade de autodesenvolvimento, a capacidade de iniciativa, o relacionamento interpessoal e a flexibilidade às mudanças.

Mais importante ainda é destacar dois pontos que podem contribuir para a formação da percepção de que a competência de visão sistêmica, enfocada na pesquisa, em termos motivacionais, não é tão atraente como outros desempenhos ou comportamentos concorrentes. O primeiro ponto é a dificuldade de determinação articulada de metas no setor público, cujas características estruturais e contextuais tendem a cercear uma atuação mais gerencialista de suas unidades constituintes. O segundo, a imprecisão dos critérios comportamentais apontados no decreto, também refletidos em normativos anteriores sobre a função de gestão do desempenho na administração pública. Com isso, o relacionamento interpessoal, por exemplo, capaz, em culturas nas quais coexistem valores patrimonialistas e burocráticos (CARBONE, 2000), de exercer maior impacto sobre as avaliações de desempenho individuais em contextos da administração pública, pode ser uma competência mais atraente aos servidores.

Outra explicação alternativa para a ausência de relações entre motivação e necessidades de treinamento refere-se ao nível de comprometimento com a organização por parte dos servidores com menos tempo de trabalho. Em estudo sobre o comprometimento com o trabalho em vários contextos organizacionais, Bastos e Borges-Andrade (2002) encontraram que a organização burocrática clássica (quatro órgãos da administração pública centralizada foram pesquisados) apresentou elevada concentração de seus funcionários (68\%) nos padrões caracterizados por reduzido comprometimento organizacional. Além disso, dos quatro contextos organizacionais estudados, este que incluía os quatro órgãos da administração pública foi o que apresentou maior contingente de comprometidos apenas com a carreira.

Dessa forma, pode ser que o comprometimento com a carreira, no caso dos servidores com menos tempo de trabalho, seja maior do que com a organização. É sabido que dentre os cargos públicos, aqueles integrantes do Poder Executivo, como é o caso da autarquia pesquisada, são os menos almejados, talvez por proporcionarem aos seus funcionários salários 
Necessidades de treinamento organizacional e motivação para trabalhar

e benefícios menores do que os praticados nos demais poderes. É de senso comum também que, geralmente, os indivíduos que estudam para concursos públicos buscam ser aprovados em vários processos seletivos para poder, então, escolher o órgão mais vantajoso para trabalhar, pelo menos do ponto de vista remuneratório. Tendo em vista, ainda, que estatísticas da área de Gestão de Pessoas da organização revelam alto índice de vacância dos cargos das novas carreiras por motivo de posse em outro cargo público, pode-se especular que os servidores com menos tempo de trabalho sintam necessidades de treinamento não para obterem um melhor desempenho no trabalho, e sim para alcançarem melhores desempenhos em provas de concurso para outros órgãos.

Assim, o que se considera mais provável é que os servidores novatos não tenham a intenção de se qualificar ainda mais para desenvolver atividades em uma autarquia cujo vencimento básico não se equipara a valores praticados por outros órgãos da administração pública federal e mesmo pela iniciativa privada. Apesar de não serem considerados antecedentes diretos de intenção de rotatividade (FERREIRA; SIQUEIRA, 2005), é provável que os altos salários praticados por determinados órgãos da administração pública, sobretudo no cenário de Brasília, onde a pesquisa fora realizada, marcadamente constituído por recorrentes e diversificadas ofertas de emprego que exigem basicamente o domínio de conhecimentos similares, a exemplo de direito civil, constitucional e administrativo, salvo algumas especificidades inerentes à função do órgão alvo (regimento interno, por exemplo), estejam direcionando as atenções dos novos ocupantes da Autarquia para essa perspectiva apenas.

Em suma, como não se constatou associação entre as variâncias das respostas dos participantes aos instrumentos de motivação para trabalhar e de necessidades de treinamento, não pôde ser totalmente testada, sendo refutada antes das análises finais, a especulação de que indivíduos mais motivados apresentariam necessidades de treinamento mais complexas. Os índices da força motivacional demonstraram variabilidade dos níveis de motivação para o trabalho. Entretanto, os resultados do instrumento de ANT, como já demonstrado anteriormente pelo valor das médias dos índices de prioridade, não revelaram discrepância significativa entre os diferentes níveis de complexidade, impedindo que fosse testada a relação entre motivação para o trabalho e complexidade de necessidades de treinamento. De qualquer forma, o fato de não haver relação entre motivação e necessidades de treinamento exige uma maior reflexão sobre as pesquisas que confirmaram a predição de desempenho por variáveis referentes à motivação. 


\section{CONSIDERAÇÕES FINAIS}

Responsável por prover informações para as etapas de planejamento e execução e de avaliação de efeitos, o subsistema de avaliação de necessidades de TD\&E assume fundamental importância para a efetividade de todas as ações da área. Diante da importância atribuída à ANT e das poucas pesquisas que relacionaram características da clientela com necessidades de treinamento e, ainda, do fato de que nenhuma dessas pesquisas valeu-se de variáveis motivacionais, o estudo que gerou este artigo teve como propósito analisar o relacionamento entre motivação para trabalhar e necessidades de treinamento, organizadas conforme nível de complexidade. A tentativa de alcançar esse objetivo foi viabilizada com a construção de um instrumento de ANT, validação de um instrumento de motivação para trabalhar e coleta de dados em uma autarquia pública.

Nesse sentido, destaca-se que a elaboração e validação semântica e estatística de um instrumento de ANT como importante contribuição desta pesquisa. Principalmente por dois motivos: primeiro, porque são raras as iniciativas dessa natureza, sobretudo agregando ao processo as taxonomias de objetivos educacionais aplicadas à etapa de planejamento instrucional; segundo, pela eficiência das orientações constantes da Metodologia de Análise do Papel Ocupacional proposta por Borges-Andrade e Lima (1983) no sentido de determinação de CHAs e os índices de prioridade de treinamento decorrentes. É preciso enfatizar, portanto, que o conteúdo do instrumento sobre visão sistêmica é pertinente a qualquer organização, podendo ser facilmente adaptado e aplicado em pesquisas futuras ou na prática.

A adaptação e a validação estatística do instrumento de medida elaborado por Queiroga (2009) também devem ser ressaltadas pela confirmação das estruturas parcimoniosas e fidedignas das escalas de valência, instrumentalidade e expectativa, obtidas pela proponente original. Essa confirmação indica a possibilidade de utilização das escalas tanto em futuras pesquisas, quanto em organizações interessadas no delineamento de políticas e intervenções na área de gestão de pessoas, cujas funções, ante o atual processo de transição de uma perspectiva utilitarista-tecnicista para outra de base humanista-desenvolvimentista, exigem não apenas a orientação para resultados organizacionais, mas, sobretudo, a articulação desse foco com as características, os anseios, os objetivos etc. de seu corpo funcional.

A proposta de modelagem da pesquisa também foi bem sucedida à medida que foram constituídos os grupos de comparação em função de diferenças estatisticamente significativas 
Necessidades de treinamento organizacional e motivação para trabalhar

no nível de motivação para o trabalho. Além disso, o fato de o tempo de trabalho ter sido identificado como variável de controle estatístico a ser incluída no modelo de investigação, a fim de reduzir as ameaças à validade interna desta pesquisa, colaborou com o sucesso do modelo. Neste caso, quando grupos de comparação não são aleatoriamente formados, corre-se sempre o risco de que atributos individuais não devidamente controlados, como o tempo de serviço no caso desta pesquisa, entre outras tantas variáveis, interfiram indevidamente na relação pretendida. Portanto, recomenda-se cautela no desenho desses tipos de pesquisa.

Apesar de cumpridos esses objetivos e da cautela empregada na execução metodológica da pesquisa, o objetivo geral foi apenas parcialmente alcançado. Não se constatou dispersão suficiente dos índices de prioridade de treinamento em visão sistêmica para que a relação entre esses índices, associados a descritores comportamentais de graus diferenciados de complexidade do desempenho embutido, e motivação para trabalhar fosse testada.

Este resultado, de qualquer forma, pode ser considerado uma importante contribuição deste estudo à medida que indica caminhos futuros para a modelagem de pesquisas que tratem da relação entre motivação e desempenho. Como antes mencionado, apesar de a motivação, ao lado das condições e capacidades, ser considerada um preditor direto de desempenho humano no trabalho, talvez seja mais sensato modelar tal variável como mediadora, moderadora ou controladora da relação entre desempenho, aqui representado pelo construto de necessidades de treinamento, e condições, estas sim, em consonância com as teorias motivacionais cientificamente válidas, responsável por maiores ou menores taxas de desempenho. Diferentemente da maioria dos resultados de pesquisas, tanto nacionais quanto internacionais, que afirmaram existir relacionamento robusto entre motivação e desempenho, ainda que não tenham sido feitas no campo de TD\&E, o resultado desta pesquisa, na qual o desempenho foi representado por índices de necessidades de treinamento, provou o contrário. Portanto, reflexões, modelos e testes que considerem as especulações teóricas antes expostas urgem.

Funcionalmente, a ausência de correlação entre motivação para trabalhar e percepção de necessidades de treinamento talvez se tenha dado pelo fato de a pesquisa ter sido realizada em uma instituição pública, ao contrário da maioria das pesquisas aqui mencionadas. Há, na autarquia pesquisada, alguma oportunidade de crescimento por mérito, ou seja, possibilidade de ocupar funções gratificadas e cargos de chefias por ter um desempenho acima do esperado. Foi possível, pela análise dos dados sociodemográficos dos respondentes desta pesquisa, 
Gisela Gomes da Silva \& Pedro Paulo Murce Meneses

constatar que os servidores novatos já estão ocupando esses cargos de liderança na instituição. Entretanto, a quantidade de funções disponíveis na Autarquia é escassa e desproporcional em relação à força de trabalho. Assim, diante da grande concorrência interna, vários servidores podem não conseguir visualizar oportunidade de crescimento para si.

Além disso, pelo histórico das organizações burocráticas, nas quais processos de gestão, como por competências e do desempenho, apenas recentemente e muito lentamente vêm ganhando espaço, a credibilidade dos servidores na promoção por meritocracia é muito baixa. O resultado da pesquisa revelou que, apesar de haver dispositivos legais para implementação desses processos de gestão de pessoas na administração pública, esses ainda precisam ser consolidados e assimilados por todos os servidores. Talvez só então o servidor público consiga se motivar a realizar um treinamento para aprimorar seu desempenho no trabalho.

É neste contexto que o resultado deste estudo pode instigar novas reflexões sobre como a motivação do trabalhador e o seu desempenho são tratados tanto na prática quanto na academia. A presente pesquisa iniciou a discussão sobre o relacionamento entre motivação e necessidades de TD\&E. O resultado não foi o esperado e precisa de confirmação mais ampla e rigorosa, principalmente no campo da administração pública federal sediada em Brasília, local onde as inúmeras oportunidades de carreira parecem desviar o comprometimento organizacional dos servidores novatos.

Além disso, a presente pesquisa também contribuiu, do ponto de vista acadêmico, com a revisão de literatura aqui apresentada, que delineou o estado da arte da área, apontando importantes desafios e avanços, essencialmente no que se refere à análise organizacional. Como mencionado, atualmente se emprega um discurso de que as ações de treinamento devem se alinhar à estratégia organizacional para serem efetivas. Entretanto, ante a ausência de produção teórica e metodológica sobre o assunto, é provável que tal discurso não seja devidamente operacionalizado pelas organizações, que têm investido cifras cada vez maiores em ações de TD\&E, principalmente em função da adoção de novas tecnologias da informação e da comunicação que tanto têm democratizado o acesso à área.

Ainda sobre lacunas na produção teórica, um ponto crítico para a pesquisa foi a ausência de referencial teórico e resultados de pesquisa sobre o relacionamento entre características individuais, entre elas a motivação, e necessidades de treinamento. Como observado, a ANT no nível da análise individual, da mesma forma que no caso da análise organizacional, não tem atraído o interesse de estudiosos e pesquisadores há algum tempo, de 
Necessidades de treinamento organizacional e motivação para trabalhar

forma que foi preciso recorrer à literatura de avaliação de efeitos de TD\&E a fim de reunir informações que permitissem a proposição de um modelo de investigação pertinente.

Outra limitação que merece atenção refere-se ao uso de apenas uma fonte de informação sobre as necessidades de treinamento: o próprio servidor. Pelas explicações para a baixa dispersão dos índices de prioridade de treinamento apresentadas na seção anterior, é provável que a diversificação de fontes de avaliação gerasse respostas de importância e domínio dos descritores de visão sistêmica mais confiáveis. Não que os dados tenham sido realmente falseados, mas pelo menos seria possível compor índices de necessidades com base em escores compostos por percepções de atores diferentes, mecanismo que certamente culminaria em índices mais dispersos na faixa de valores possível.

Além disso, é importante ressaltar, ainda, a carência de documentos organizacionais atualizados, o que prejudicou a elaboração do instrumento de ANT, bem como o baixo índice de retorno dos questionários $(45,32 \%)$, que poderia ter sido evitado caso a coleta de dados não tivesse ocorrido durante uma greve dos servidores por melhores salários e no final de novembro e início de dezembro, meses de conclusão de trabalhos, férias e confraternizações.

Agrupadas, essas limitações e as demais discussões apresentadas anteriormente levam à elaboração de algumas recomendações para pesquisas futuras: i. analisar o relacionamento entre condições, motivação e necessidades de treinamento, tanto em visão sistêmica quanto em outras categorias de competência, em diferentes organizações, do setor público e privado, para efeitos de comparação de resultados; ii. investigar a relação entre tempo de trabalho e motivação para trabalhar; iii. diversificar as fontes de avaliação de necessidades de treinamento e estudar, por meio de escores específicos a uma única fonte ou agregados, a relação entre motivação para o trabalho e necessidades de treinamento; e iv. incluir outras variáveis individuais, como comprometimento organizacional e com a carreira, na composição de modelos explicativos de necessidades de treinamento.

Por fim, espera-se que a presente pesquisa tenha contribuído com a área de avaliação de necessidades de treinamento, bem como sirva de estímulo a outros pesquisadores interessados em avaliar os efeitos de características individuais na emergência de necessidades de treinamento. Espera-se, ainda, que os instrumentos disponibilizados sirvam de subsídio para a tomada de decisão na área de gestão de pessoas e de TD\&E e que os resultados apresentados resultem em maior atenção às características da clientela antes de se planejar e executar ações de treinamento. 


\section{REFERÊNCIAS}

ABBAD, G. Um modelo integrado de avaliação do impacto do treinamento no trabalho IMPACT. Tese (Doutorado em Psicologia) - Instituto de Psicologia, Universidade de Brasília. Brasília, 1999.

ABBAD, G.S.; BORGES-ANDRADE, J.E. Aprendizagem humana em organizações e trabalho. In: ZANELLI, J.C.; BORGES-ANDRADE, J.E.; BASTOS, A.V.B. (Org.). Psicologia, Organizações e Trabalho no Brasil. Porto Alegre - RS, p. 237-275, 2004.

ABBAD, G.S., FREITAS, I. e PILATI, R. Contexto de Trabalho, Desempenho Competente e Necessidades em TD\&E. In: BORGES-ANDRADE, Jairo Eduardo; ABBAD, Gardênia da Silva; MOURÃO, Luciana. (Org.). Treinamento, Desenvolvimento e Educação em Organizações e Trabalho: Fundamentos para a Gestão de Pessoas. Porto Alegre - RS, v. 1, cap. 12, p. 231-254, 2006.

AGUINIS, H; KRAIGER, K. Benefits of Training and Development for Individuals and Teams, Organizations, and Society. Annual Review of Psychology, v. 60, p. 451-474, 2009.

BASTOS, A.V.B.; BORGES-ANDRADE, J.E. Comprometimento com o trabalho: padrões em diferentes contextos organizacionais. Revista de Administração de Empresas (RAE), v. 42, n. 2, abr./jun. 2002.

BATISTA, F. F. Curso "Elaboração de Indicadores de Desempenho Institucional". Instituto Serzedello Corrêa. Mimeo. Brasília, 1999.

BLOOM, B.S.; ENGELHART, M.D.; C.A.; E.J.; HILL, W.H.; KRATHWOHL, D.R.; Taxonomia de objetivos educacionais: domínio cognitivo. Porto Alegre: Editora Globo, 1972.

BORGES, L.O.; ALVES-FILHO, A.; TAMAYO, A. Medidas do Comportamento Organizacional - Ferramentas de Diagnóstico e de Gestão. Porto Alegre: Artmed, 2008.

BORGES-ANDRADE, J.E. Competência técnica e política do profissional de TD\&E. In: BORGES-ANDRADE, Jairo Eduardo; ABBAD, Gardênia da Silva; MOURÃO, Luciana. (Org.). Treinamento, Desenvolvimento e Educação em Organizações e Trabalho: Fundamentos para a Gestão de Pessoas. Porto Alegre - RS, v. 1, cap. 9, p. 177-195, 2006.

BORGES-ANDRADE, J.E.; LIMA, S.M.V. Avaliação de necessidades de treinamento: um método de análise de papel ocupacional. Tecnologia Educacional, Rio de Janeiro, v. 12 , n. 54, p. 6-22, 1983.

REAd I Porto Alegre - Edição 71 - N 1 - janeiro/abril 2012 - p. 27-62 
Necessidades de treinamento organizacional e motivação para trabalhar

BRESSER-PEREIRA, L. C. Da administração pública burocrática à gerencial. Revista do Serviço Público, v. 47, n. 1, 1996.

CAMPBELL, J.P. Personal training and developmentet. Annual Review of Psychology, v. 22, p. 565-602, 1971.

. Modeling the performance prediction problem in industrial and organizational psychology. In: DUNNETTE, M.; HOUGH, L. (Org.). Handbook of Industrial and Organizational Psychology, Palo Alto: Consulting Psychology, p. 687-732, 1990.

CARBONE, C. A universidade e a gestão da mudança organizacional a partir da análise sobre o conteúdo dos padrões interativos. Revista de Administração Pública, v. 29, n. 1, p. 34-47, jan./mar. 1995.

CARBONE, P.P. Cultura organizacional no setor público brasileiro: desenvolvendo uma metodologia de gerenciamento da cultura. Revista de Administração Pública, Rio de Janeiro, v. 34, n. 2, p.133-144, 2000.

CASTRO, P.M.R.; BORGES-ANDRADE, J.E. Identificação das necessidades de capacitação profissional: o caso dos assistentes administrativos da Universidade de Brasília. Revista de Administração - USP. v. 39, n.1, 2004.

COLQUITT, J.A.; LEPINE, J.A.; NOE, R.N. Toward an integrative theory of training motivation: a meta-analytic path analysis of 20 years of research. Journal of Applied Psychology. 85(5): 678-707, 2000.

CURY, A. Organização e Métodos: uma visão holística. São Paulo: Atlas, 2000.

FERREIRA, R. Avaliação de Necessidades de Treinamento: Proposição e Aplicação de um Modelo Teórico-Metodológico nos níveis Macro e Meso Organizacionais. Dissertação (Mestrado em Psicologia) - Instituto de Psicologia, Universidade de Brasília. Brasília, 2009.

FERREIRA, R.; ABBAD, G.; PAGOTTO, C.; MENESES, P. Avaliação de Necessidades Organizacionais de Treinamento: $\mathrm{O}$ Caso de uma Empresa Latino-Americana de Administração Aeroportuária. Revista Eletrônica de Administração - Read, 15, 2, mai-ago, 2009. 
Gisela Gomes da Silva \& Pedro Paulo Murce Meneses

FERREIRA, M. L. C. B; SIQUEIRA, M. M. M. (2005). Antecedentes de intenção de rotatividade: estudo de um modelo psicossocial. Organizações em Contexto, v. 1, n. 2, p. 4767, 2005.

GILBERT, T.F. Human Competence: Engineering Worthy Performance. New York: McGraw-Hill, 1978.

GOLDSTEIN, I.L. Training in work organizations. Annual Review of Psychology, v. 31, p. 229-272, 1980.

GONDIM, S.M.G.; BASTOS, A.V.B.; BORGES-ANDRADE, J.E.; MELO, L.C.T. Práticas inovadoras em gestão de produção e de pessoas e TD\&E. In: BORGESANDRADE, Jairo Eduardo; ABBAD, Gardênia da Silva; MOURÃO, Luciana. (Org.). Treinamento, Desenvolvimento e Educação em Organizações e Trabalho: Fundamentos para a Gestão de Pessoas. Porto Alegre - RS, v. 1, cap. 3, p. 65-84, 2006.

ISAAC, R.G.; ZERBE, W.J.; PITT, D.C. Leadership and motivation: The effective application of expectancy theory. Journal of Managerial Issues, v. 13, n. 2, p. 212-226, 2001.

LACERDA, E.R.M. Motivação, valor instrumental do treinamento, reação, suporte à transferência e impacto do treinamento no trabalho. Brasília, 2002. Dissertação (Mestrado em Psicologia) - Instituto de Psicologia, Universidade de Brasília.

LACERDA, E.R.M.; ABBAD, G.S. Impacto do Treinamento no Trabalho: Investigando Variáveis Motivacionais e Organizacionais como suas Preditoras. Revista de Administração Contemporânea - RAC, v. 7, n. 4, 77-96, 2003.

LATHAM, G. Human resource training and development. Annual Review of Psychology, v. 39, p. 545-582, 1988.

LIMA, S.V.L.; BORGES-ANDRADE, J. E. Bases conceituais e teóricas de avaliação de necessidades em TD\&E. In: BORGES-ANDRADE, Jairo Eduardo; ABBAD, Gardênia da Silva; MOURÃO, Luciana. (Org.). Treinamento, Desenvolvimento e Educação em Organizações e Trabalho: Fundamentos para a Gestão de Pessoas. Porto Alegre - RS, v. 1, cap. 10. p. 199-215, 2006.

LOIOLA, E.; NÉRIS, J.S.; BASTOS, A.V.B. Aprendizagem em organizações: mecanismos que articulam processos individuais e coletivos. In: BORGES-ANDRADE, Jairo Eduardo; ABBAD, Gardênia da Silva; MOURÃO, Luciana. (Org.). Treinamento, Desenvolvimento e Educação em Organizações e Trabalho: Fundamentos para a Gestão de Pessoas. Porto Alegre - RS, v. 1, cap. 6, p. 114-136, 2006.

REAd I Porto Alegre - Edição 71 - N 1 - janeiro/abril 2012 - p. 27-62 
Necessidades de treinamento organizacional e motivação para trabalhar

MAGALHÃES, M. L. \& BORGES-ANDRADE, J.E. Auto e heteroavaliação no diagnóstico de necessidades de treinamento. Estudos de Psicologia, Natal, v. 6, n. 1, p.33-50, 2001.

MAGER, R.F.; PIPE, P. Análise de Problemas de Desempenho. Porto Alegre - RS. Editora Globo, 1984.

MARCONI, N. A evolução do perfil da força de trabalho e das remunerações nos setores público e privado ao longo da década de 1990. Revista do Serviço Público, v. 54, n. 1, p. 9 45, 2003.

McGEHEE, W.; THAYER, P.W. Training in Business and Industry. Nova York: Wiley, 1961.

MEDEIROS, C.A.F.; ALBUQUERQUE, L.G.; SIQUEIRA, M.; MARQUES, G.M. Impacto do Treinamento no Trabalho: Investigando Variáveis Motivacionais e Organizacionais como suas Preditoras. Revista de Administração Contemporânea - RAC, v. 7, n. 4, 187-209, 2003.

MENESES, P.P.M; ZERBINI, T.; ABBAD, G. Manual de treinamento organizacional. Porto Alegre, Artmed, 2010.

MOORE, M.L.; DUTTON, P. Training Needs Analysis: Review and Critique. Academy of Management Review, v. 2, p. 532-545, 1978.

NOGUEIRA, P.R. Necessidades de treinamento: construção e validação de um instrumento. Arquivos Brasileiros de Psicologia, v. 34, n. 4, p. 46-65, 1982.

PARKER, S. K.; TURNER, N. Work design and individual job performance: Research findings and an agenda for future inquiry. In S. SONNENTAG (Ed.). Psychological Management of Individual Peformance: A Handbook in the Psychology of Management in Organizations. John Wiley \& Sons: Chichester, UK, p. 69-94, 2002.

PASQUALI, L. Teses Referentes a Construto: Teoria e Modelo de Construção. In: PASQUALI, L. (Org.). Instrumentos Psicológicos: Manual Prático de Elaboração. Brasília: LabPAM, p. 37-72, 1999. 
PILATI, R. História e Importância de TD\&E. In: BORGES-ANDRADE, Jairo Eduardo; ABBAD, Gardênia da Silva; MOURÃO, Luciana. (Org.). Treinamento, Desenvolvimento e Educação em Organizações e Trabalho: Fundamentos para a Gestão de Pessoas. Porto Alegre - RS, v. 1, cap. 8, p. 159-176, 2006.

PIRES, J. C. S; MACÊDO, K. B. Cultura organizacional em organizações públicas no Brasil. Revista de Administração Pública, v. 40, n. 1, p. 81 - 105, 2006.

QUEIROGA, F. Seleção de pessoas e desempenho no trabalho: um estudo sobre a validade preditiva de testes de conhecimentos. Tese (Doutorado em Psicologia) - Instituto de Psicologia, Universidade de Brasília. Brasília, 2009.

RIBEIRO, R.L. Motivação para Aprendizagem Informal no Trabalho: construção de medidas e investigação de modelo teórico. $170 \mathrm{f}$. Dissertação (Mestrado em Psicologia) - Universidade de Brasília. 2005.

SALAS, E.; CANNON-BOWERS, J. The science of training: a decade of progress. Annual Review of Psychology, v. 52, p. 471-499, 2001.

SALLORENZO, L.H. Avaliação de impacto de treinamento no trabalho: analisando e comparando modelos de predição. Brasília, 2000. Dissertação (Mestrado em Psicologia) Instituto de Psicologia, Universidade de Brasília.

TABACHNICK, B. G.; FIDELL, L. S. Using Multivariate Statistics. Boston: Allyn \& Bacon. 2001.

TANNENBAUM, S.; YUKL, G. Training and development in work organizations. Annual Review of Psychology, v. 43, p. 399-441, 1992.

TAO, Y.; YEH, C.R.; SUN, S. Improving training needs assessment processes via the Internet: system design and qualitative study. Emerald Insight. Internet Research. v. 16, n. 4, p. 427-449, 2006.

TAYLOR, P.; O’DRISCOLL, M.P.; BINNING, J. A new integrated framework for training needs analysis. Human Resource Management Journal, v. 8, n. 2, p. 29-50, 1998.

VROOM, V.H. Work and motivation. New York: Wiley, 1964. 
Pág in a | 62

Necessidades de treinamento organizacional e motivação para trabalhar

WEXLEY, K. N. Personnel training. Annual Review of Psychology, v. 35, p. 519-551, 1984.

REAd I Porto Alegre - Edição 71 - N 1 - janeiro/abril 2012 - p. 27-62 